\title{
How much does weather control fire size and intensity in the Mediterranean region?
}

\author{
C. Hernandez, P. Drobinski, and S. Turquety \\ Institut Pierre Simon Laplace/Laboratoire de Météorologie Dynamique, CNRS/Ecole Polytechnique/Université Pierre et \\ Marie Curie, Palaiseau, France \\ Correspondence to: C. Hernandez (charles.hernandez@1md.polytechnique.fr)
}

Received: 5 May 2015 - Revised: 6 July 2015 - Accepted: 9 July 2015 - Published: 30 July 2015

\begin{abstract}
This study investigates the synoptic conditions favorable to wildfires in the Mediterranean region, in terms of fire intensity and burnt area. As reported in the literature, Mediterranean large wildfires are associated with a blocking situation. However, this study shows the existence of two types of wildfires controlled by the blocking high intensity: (1) fast build-up of a weak blocking produces intense wildfires associated with strong winds which allow propagation over long distances; (2) longer build-up of strong blocking situation produces less intense wildfires associated with weaker winds which also propagate over long distances. Another major step forward of this study in the understanding of the drivers of those wildfires is the evidence of a perfect match between the period of wildfire activity and the persistence of the favorable synoptic conditions: the wildfire activity starts at the onset of the blocking situation and ends with the transition to a less favorable synoptic weather pattern. Such strong control of the wildfire activity by the concomitant weather is a very promising result regarding fire risk management, especially considering the accidental nature of the Mediterranean wildfires.
\end{abstract}

Keywords. Meteorology and atmospheric dynamics (synoptic-scale meteorology)

\section{Introduction}

Fire is the most important natural threat to forests and wooded areas of the Mediterranean basin. It destroys many more trees than all other natural calamities: parasite attacks, insects, tornadoes, frost, etc. Vegetation fires burnt an average 200000 ha annually in the Mediterranean Basin between 1960 and 1970; the figure attained over 400000 ha in the
1970 's and over 600000 ha in the 1980's. This three fold increase over 20 years is turning into an annual summer catastrophe in the Basin, in spite of heavy investments and large budget expenditure spent to prevent and combat the scourge (Le Houérou, 1987). The 2003 wildfires of Portugal are a good example of the amount of damage that large wildfires can cause in the Mediterranean region. More than $57 \%$ of the burnt area in the EU occurred in Portugal that year and over 420000 ha were burnt (EFFIS, 2003), with an accumulated cost amounting to EUR 1 billion (UNEP, 2004).

Wildfires are conditioned by many factors such as topography, land use (Carmo et al., 2011) and also past and concomitant weather (Flannigan et al., 2009). They control the spread and thus the size of the fire and also its intensity. The size of the fire is a diagnostic of the large and long-lasting imprints of the fire on the environment. We cannot directly retrieve the intensity for a large number of fires. Instead we will focus on a related diagnostic, the fire radiative power (FRP). The FRP is a diagnostic of the biomass combustion rate (Wooster et al., 2005; Ichoku et al., 2008), controls the emissions that wildfires release in the atmosphere (Turquety et al., 2014) and partly explains their injection height (Val Martin et al., 2010). Weather during the fire episode is essential. Indeed, the wind speed determines the rate of spread of the fire and the fire-line intensity (Rothermel, 1972). A few weeks before the fire episode, wind speed, insolation, humidity and temperature influence fuel moisture by controlling water fluxes in dead and live fuels (Castro et al., 2003; Matthews, 2006; Aguado et al., 2007; Sharples et al., 2009) whereas few months to several years before, they mainly control the vegetation growth and so the fuel amount. For instance, Stéfanon et al. (2012b) show that a springtime meteorological drought characterized by several months of cloudi- 
ness and precipitation deficit lead to unusually high solar radiation which is beneficial for vegetation growth, as measured in terms of leaf-area index. Zaitchik et al. (2006) also confirmed this finding using satellite observations of vegetation. In 2003, this unusual excess of vegetation lasted until the end of July when the vegetation started dying leading to a large fuel amount and low fuel moisture, making it favorable to high fire risk. Meteorological conditions propitious to high fire risk have already been investigated in previous work. Flannigan and Wotton (2001) showed that warm, dry and windy days are correlated to higher burnt area, and that certain synoptic conditions such as the breakdown of an upper blocking ridge lead to particularly favorable conditions for wildfires. Before this work, Flannigan and Harrington (1988) already observed that, in Canada, high fire risk was associated with long sequences of dry and low precipitations days. In the Mediterranean region, Pereira et al. (2005) found that days with large burnt area in Portugal are concomitant with atmospheric blocking regimes in summer. These findings are corroborated with Hoinka et al. (2009) and Levin and Saaroni (1999), which find characteristic synoptic patterns associated with wildfire occurrence in Iberia and Israel, respectively.

However, the existence of favorable weather conditions does not tell us how much these favorable conditions control the life cycle of a fire, in terms of size and intensity. This is a key issue when trying to improve fire risk forecast or support to forest fire fighting. In this article we thus address the following questions:

- Are the meteorological driving factors of fire size and fire intensity similar?

- How much is the life cycle of wildfires controlled by weather variability around its most favorable pattern?

\section{Methodology}

\subsection{Data}

Our weather database was built upon the ERA-Interim reanalysis of the European Center for Medium-range Weather Forecast (ECMWF) (Dee et al., 2011). For each day of detected wildfire, we use the surface wind speed and temperature, as well as the $500 \mathrm{hPa}$ geopotential height and wind speed at 12:00 UTC. These data allow the characterization of the synoptic weather conditions associated with the fire episode, as well as an indication of the meteorological environment of the fire at the surface. The horizontal resolution of the reanalysis does not allow the derivation of the small-scale weather conditions in the immediate vicinity of the fire. The detection of fires is performed using the fire products from MODIS (Moderate Resolution Imaging Spectroradiometer), an instrument carried on board the Aqua and Terra polar heliosynchronous orbiting satellites. These prod-

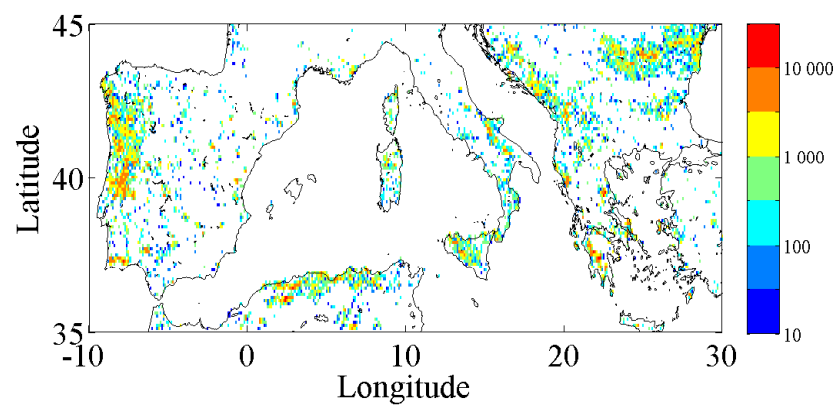

Figure 1. 10-years accumulated burnt area (in ha) from MODIS MDC64 product over the Mediterranean region (2003-2012).

ucts are the burnt area (BA) and the fire radiative power (FRP) which can be seen as a proxy of the fire intensity. The FRP is retrieved by using measured radiance of the 4 and $11 \mu \mathrm{m}$ channels at nadir. Other spectral bands are used for assessing cloud masking, glint, bright surface and other sources of false alarms and disturbances. The FRP is provided at $1 \mathrm{~km}$ resolution by the MOD14 product. The BA is retrieved from the observed changes in land cover. Indeed, the albedo is modified by the deposition of charcoal and ash, the loss of vegetation and the change in fuel bed characteristics.

Albedo alteration produces changes in surface reflectance which are processed to produce daily burnt area at a $500 \mathrm{~m}$ resolution in the MDC64 product (Giglio et al., 2010). Only the fraction of the detected burning pixel covered by vegetation is burned following Turquety et al. (2014). The FRP and BA products are then regridded at $10 \mathrm{~km}$ resolution which was chosen to be a good trade-off in order to keep detailed enough information on the fire location and facilitate the comparison with the ERA-Interim meteorological data. We use the first 10 years (2003-2012) of MODIS data. As small wildfires are difficult to detect with satellite observations, wildfires with sizes smaller than 25 ha were eliminated from our BA data set. Figure 1 shows the accumulated burnt areas as retrieved by MODIS for the first 10 years of data (2003-2012). Figure 2 shows the total burnt area, mean fire intensity and associated fire counts for the 2003-2012 time period. We see that fire intensity and the associated number of fires have low interannual variability whereas burnt area is dominated by 4 extreme events, years 2003, 2005, 2007 and 2012. It should be noted that there are important uncertainties on the date of beginning of wildfires taken individually. The incertitude can be as large as 5 days and is caused by several factors such as cloud cover impairment of remote sensing and lack of detection of wildfires at the beginning of their development. As we deal with statistics (average, ...) on large number of such wildfires, the uncertainty is reduced. We also use the EFFIS (European Forest Fire Information System) Rapid Damage Assessment system, provided by the Joint Research Center (JRC) of the 

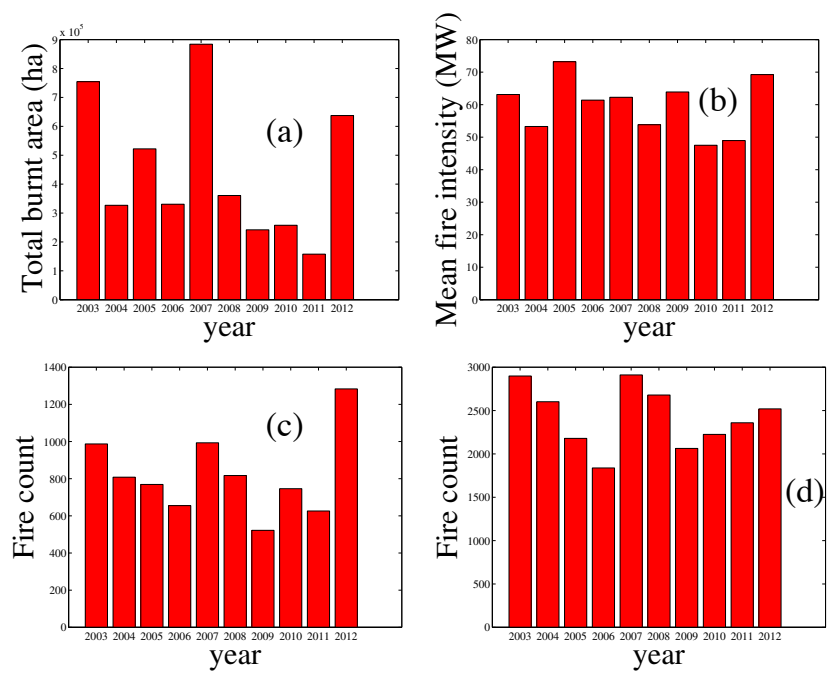

Figure 2. Total burnt area (a), fire intensity (b) and fire counts associated with BA (c) and FRP (d) detection for the 2003-2012 time period. BA detection is done using the MODIS MCD64 product.

European Commission (2010). This set is built using 250$\mathrm{m}$ MODIS images. A first step of automated classification is used to isolate fire events and a post-processing using human visualization of the burnt scar is performed. A crossanalysis using the active fire MODIS product, land-cover data sets as well as fire event news collected in the EFFIS News module is finally done to ensure a low number of misclassifications (http://forest.jrc.ec.europa.eu/effis/). The system records burnt areas of approximately $40 \mathrm{ha}$ and larger (Sedano et al., 2013). The JRC provided the data for the 2006-2012 time period. In this study we only take into account wildfires recorded in July and August, so as to focus on the summer period when most large wildfires can be found in the Mediterranean.

\subsection{Processing}

A 3-D (latitude, longitude and time) connected component algorithm is used to determine what are the distinct fire events in the MODIS data set. This method groups adjacent cells of $10 \mathrm{~km} \times 10 \mathrm{~km}$ spatial resolution and 1-day time resolution within which a fire is detected. The main interest of this method is that it allows for the detection of wildfires larger than $10000 \mathrm{ha}(10 \mathrm{~km} \times 10 \mathrm{~km})$ and extending over more than 1 day. These fires are those expected to be most influenced by weather conditions (e.g. Pereira et al., 2005). The main weakness is that it does not take into account cloud cover impairment of remote sensing. Indeed an absence of detection of 1 day between two detections could be caused by clouds. Another problem is that two independent fire events taking place close to one another (less than $20 \mathrm{~km}$ of distance and less than a day between the end of the first event and the beginning of the second) are considered the same by this method. Megafire events, such as defined by San-MiguelAyanz et al. (2013), could also be grouped in clusters with this method of analysis. In this work we will often work using the date of beginning of the wildfires $\left(t_{0}\right)$ and its duration $(\Delta t)$. The date of beginning will be the date of first detection of the fire event and the duration the number of consecutive days of detection. For fires in the Mediterranean Basin (MODIS set) the mean duration is approximately 2.5 days.

The processing of the EFFIS data set is simpler. The data set provides the shape and time of beginning of all detected wildfires. The centroid of this shape is taken as the location.

The relationship between burnt area and intensity, and the driving meteorological variables (temperature anomaly and wind speed) is derived by combining a burning fire event and the nearest meteorological data from the ERA-Interim reanalysis at 12:00 UTC of the first day of fire detection.

Temperature and geopotential anomalies were computed using a daily timescale climatology.

\section{Fire and weather drivers}

Figure 3 displays the variations of the 95th quantile of the $\mathrm{BA}$ at the end of the fire and the FRP at the fire mature stage (first day) with respect to the $10 \mathrm{~m}$ wind speed at 12:00 UTC on the first day of each fire over the whole Mediterranean region. The focus on the largest and most intense fires is justified as these fires are the most dependent on the meteorology. The quantities BA and FRP are clustered in two categories of $2 \mathrm{~m}$ temperature anomaly with respect to the climatology $\left(\Delta T_{2}\right)$, i.e. $\Delta T_{2}<3$ and $\Delta T_{2}>3{ }^{\circ} \mathrm{C}$. However, a $3{ }^{\circ} \mathrm{C}$ temperature anomaly represents the 75 th percentile of the temperature anomaly CDF (Stéfanon et al., 2014). It thus includes all heatwaves, among them the most severe ones. For each subfigure the data are separated in seven bins of an equal number of fires. The 95th quantile and its corresponding $70 \%$ (BA) and $90 \%$ (FRP) confidence intervals are then computed using 1000 bootstrap resamplings. Those confidence levels correspond to the maximum levels of significance possible for each subplot.

Figure 3 shows a general growth with respect to the $2 \mathrm{~m}$ temperature anomaly in most cases. Indeed, BA ranges between 1500 and 1800 ha for $\Delta T_{2}<3^{\circ} \mathrm{C}$ and between 1800 and 4000 ha for $\Delta T_{2}>3^{\circ} \mathrm{C}$. This is explained by the fact that high values of $\Delta T_{2}$ imply, during summer, the presence of a drought (Stéfanon et al., 2012a) and therefore strong fuel drying over large regions. Figure 3 also shows a peculiar dependence of BA with respect to wind speed in the Mediterranean region. For a low temperature anomaly $\left(\Delta T_{2}<3{ }^{\circ} \mathrm{C}\right)$, BA increases with surface wind speed. Since the rate of fire spread is a growing function of the ambient wind, stronger winds should produce larger wildfires (Rothermel, 1972). Conversely, for a high temperature anomaly $\left(\Delta T_{2}>3{ }^{\circ} \mathrm{C}\right)$, the evolution of BA as a function of wind speed is bimodal. Large values of BA around 3000 ha are found for low wind 
Table 1. Table of median BA values, duration and propagation rate of HWM and WFM wildfires. We take only the wildfires with a size in the top $10 \%$.

\begin{tabular}{lcc}
\hline Parameter & Heat wave mode (HWM) & Wind-forced mode (WFM) \\
\hline Number of wildfires & 98 & 67 \\
Median size (ha) & $2731 \pm 255$ & $2039 \pm 223$ \\
Median duration (days) & $8.36 \pm 0.47$ & $6.96 \pm 0.27$ \\
Median propagation rate $\left(\right.$ ha d $\left.^{-1}\right)$ & $349 \pm 34$ & $385 \pm 44$ \\
\hline
\end{tabular}
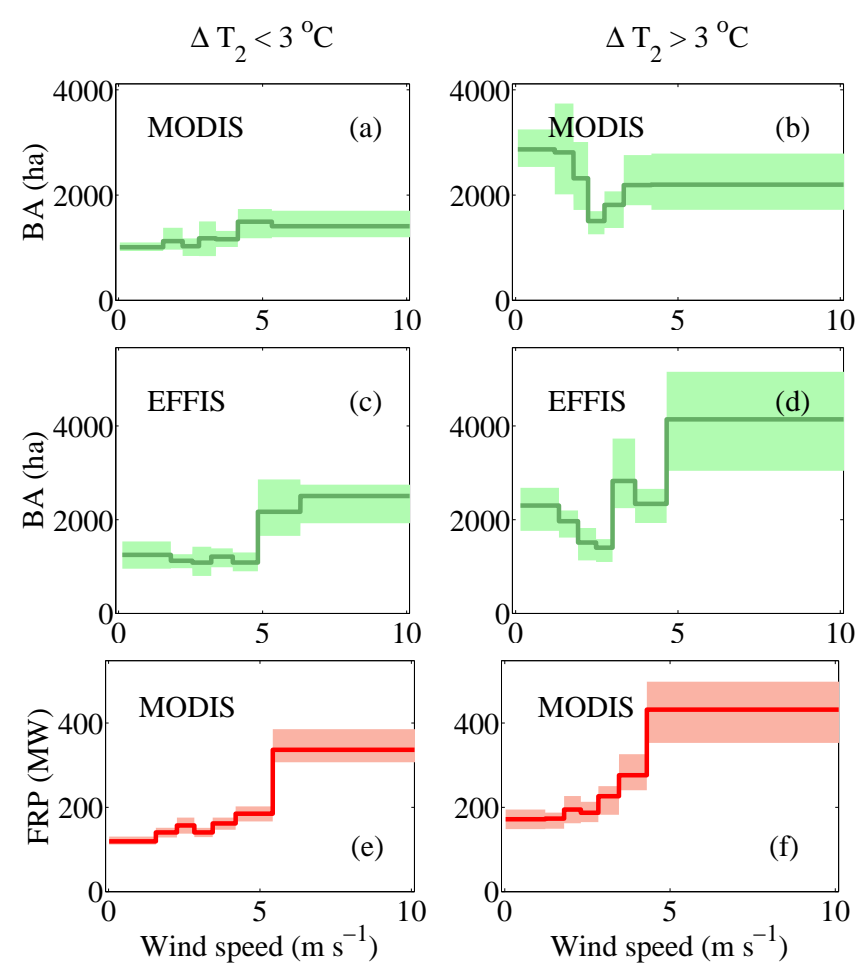

Figure 3. Burnt area (BA) at the end of the fire (upper and middle rows, $\mathbf{a}, \mathbf{b}, \mathbf{c}$ and $\mathbf{d}$ ) and fire radiative power (FRP) at the fire mature stage (first day) (lower row, e and f) with respect to the $10 \mathrm{~m}$ wind speed at 12:00 UTC on the first day of each fire over the whole Mediterranean region. For BA the upper row corresponds to the MODIS data set and the middle row to the EFFIS data set. The solid line represents the 95th quantiles $\left(q_{95}\right)$ of BA (upper and middle row) and FRP (lower row). The green shaded area represents the $70 \%$ confidence intervals (BA) and the red shaded area the $90 \%$ confidence intervals (FRP). The quantities BA and FRP are clustered in two categories of $2 \mathrm{~m}$ temperature anomaly with respect to the climatology $\left(\Delta T_{2}\right)$, i.e. $\Delta T_{2}<3{ }^{\circ} \mathrm{C}$ (left column) and $\Delta T_{2}>3{ }^{\circ} \mathrm{C}$ (right column). For each subfigure the data are separated in seven bins of equal number of fires.

speed $\left(<2 \mathrm{~m} \mathrm{~s}^{-1}\right.$ in ERA-Interim), followed by smaller values around 1800 ha for intermediate wind speed (between 2 and $4 \mathrm{~m} \mathrm{~s}^{-1}$ in ERA-Interim), followed by larger values again around 2200 ha for large wind speed (between $>4 \mathrm{~m} \mathrm{~s}^{-1}$ in ERA-Interim). In the following, in case the temperature anomaly exceeds $3^{\circ} \mathrm{C}$, the situation corresponding to a wind speed weaker than $2 \mathrm{~m} \mathrm{~s}^{-1}$ will be referred as the heatwave mode (HWM), whereas the situation corresponding to a wind speed stronger than $4 \mathrm{~m} \mathrm{~s}^{-1}$ will be referred as the windforced mode (WFM). Such behavior has been discussed in Hernandez et al. (2015) and elements of explanation have been proposed. As can be seen in Table 1, the HWM wildfires have a longer duration than the WFM wildfires, they can therefore burn over larger areas. Indeed, in the absence of strong wind speed, there is then no dominant direction of propagation. Thus, those wildfires can, albeit more slowly than WFM wildfires, expand in all directions and burn a large area since they have a lower probability to be stopped in all directions than in one specific propagation direction. The local minimum for moderate values of wind speed is due to the strong reduction in back-propagation of the fires which is not compensated by the enhancement in forward propagation.

The behavior of FRP is simpler than that of BA since this quantity is the instantaneous response of the fire intensity with regard to its environment. Like BA, FRP also increases with the temperature anomaly. FRP ranges between 150 and $350 \mathrm{MW}$ for $\Delta T_{2}<3^{\circ} \mathrm{C}$ and between 200 and $400 \mathrm{MW}$ for $\Delta T_{2}>3^{\circ} \mathrm{C}$. This is due to the fact that dryer fuels mean higher fire intensity. Therefore the FRP is larger with these dryer fuels, as less energy is wasted for water evaporation. And since the rate of spread is also a growing function of the ambient wind, high surface winds mean higher fire intensity, hence higher FRP, with consequences on fire combustion emission injection height (Val Martin et al., 2010).

The synoptic conditions associated with these observed maxima of BA and FRP are shown in Fig. 4 for the Iberian Peninsula, as it represents more than half of the burnt area of the European Union (Silva et al., 2010; EFFIS, 2003). Figure 4 represents composites of the 500-hPa geopotential height anomaly and of temperature anomaly for initiating HWM and WFM wildfires. It clearly shows that the HWM wildfires are associated with synoptic blocking with a high-pressure anomaly pattern located over Western Europe, which resembles the pattern of Pereira et al. (2005) and Stéfanon et al. (2012a) (e.g. Western Europe cluster in Fig. 2).

The WFM wildfires are also associated with a blockinglike pattern with, however, a weaker anticyclonic anomaly elongated along a curved ridge. The HWM and WFM wildfires are totally distinct fire episodes as will be shown in the following section. One can eventually notice that the pattern 


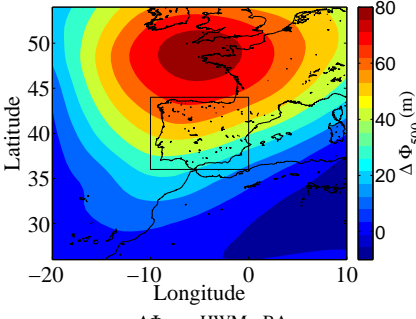

$\Delta \Phi_{500}$ - HWM - BA
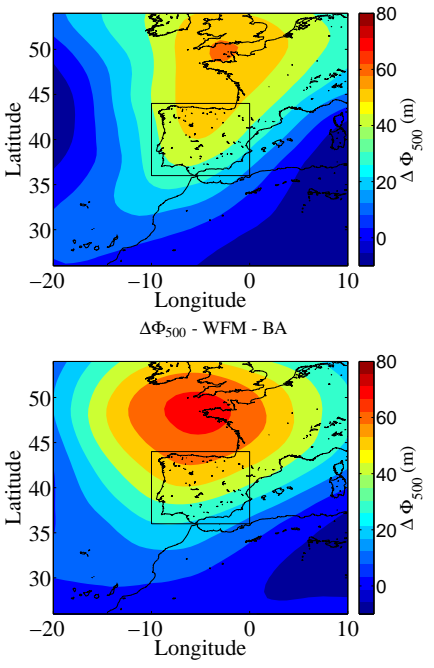

$\Delta \Phi_{500}$ - HWM - FRP
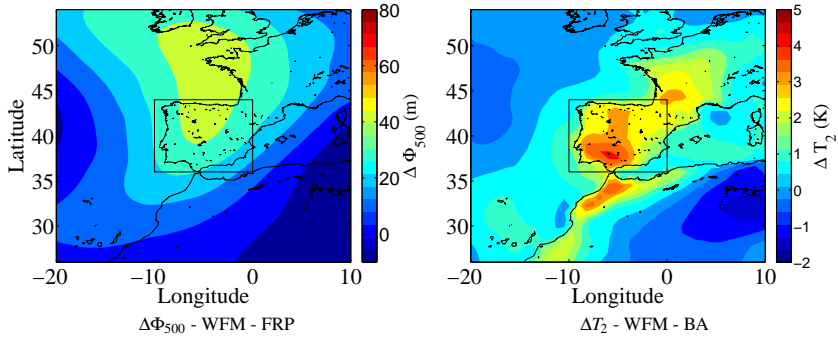

Figure 4. Composites over the Iberian Peninsula of the 500-hPa geopotential anomaly $\left(\Delta \Phi_{500}\right)$ (left column) and the $2 \mathrm{~m}$ air temperature $\left(\Delta T_{2}\right)$ (right column) for BA diagnostic corresponding to HWM (first row from top) and WFM (second row from top) and for FRP diagnostic corresponding to HWM (third row from top) and WFM (fourth row from top).

is not sensitive to the fire diagnostic, i.e. BA or FRP, used to compute the composites. Finally, the favorable conditions corresponding to the extreme wildfires are similar to those found in Pereira et al. (2005). Student's $t$ tests were performed in Fig. 4 to determine if these composites are statistically different from the climatology. We find that they are at the $99.9 \%$ confidence level. Composites of HWM and WFM are also statistically different at the $99.9 \%$ confidence level.

Figure 5 shows the total burnt area, mean fire intensity and associated fire counts for fires classified in either HWM or WFM. Over the 2003-2012 period, the figure shows that on average, the number of fires associated with HWM is slightly larger than the number of fires associated with WFM. HWM
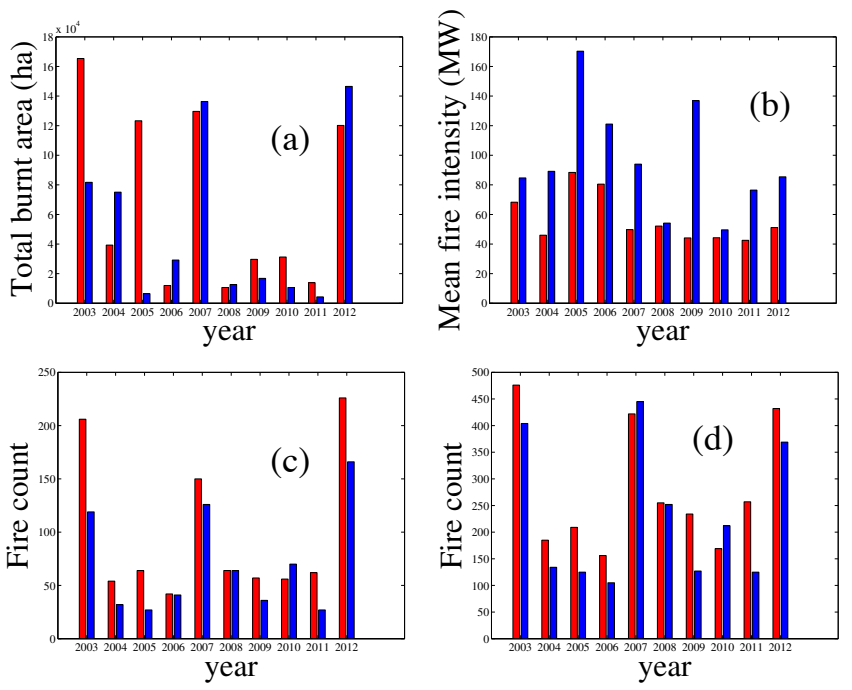

Figure 5. Total burnt area (a), fire intensity (b) and fire counts associated with BA (c) and FRP (d) detection for HWM (red) and WFM (blue). BA detection is done using the MODIS MCD64 product.

mode fires contributed significantly more to the burnt area for years 2003 and 2005. Interestingly, year 2007 is remarkable in terms of total burnt area but it is well balanced between the two modes. Such behavior is not reproduced when looking at the fire intensity. For all years, the most intense fires are associated with WFM mode fires.

How strongly these favorable conditions control the life cycle of the fire episode is still an open question, especially considering that wildfires in the Mediterranean region are generally caused by accidents (Le Houérou, 1987; Silva et al., 2010; Ganteaume et al., 2013).

\section{Fire life cycle and weather variability}

Figure 6 shows the time sequences of the composites over the Iberian Peninsula of the 500-hPa geopotential height anomaly for HWM and WFM wildfires. The composite charts are shown at time $t_{0}-3 \Delta t, t_{0}-\Delta t, t_{0}, t_{0}+\Delta t$ and $t_{0}+3 \Delta t$, with $t_{0}$ as the fire starting date and $\Delta t$ the fire duration. As shown before in Fig. 4, the patterns are identical when the FRP diagnostic is used and is thus not shown.

This example for the Iberian Peninsula will be generalized in the following. In the HWM situation, Fig. 6 shows the build-up of the blocking high north of the Peninsula a few days before the wildfire episode but still remains weak $\left(t_{0}-3 \Delta t\right.$ to $\left.t_{0}-\Delta t\right)$. The anticyclonic anomaly strengthens very quickly at the time of the wildfire $\left(t_{0}\right)$ and weakens quickly at the end $\left(t_{0}+\Delta t\right)$. The anomaly disappears a few days after the episode $\left(t_{0}+3 \Delta t\right)$. The sequence for the WFM situation is very similar, except that the build-up of the blocking high is shorter (about $\Delta t$ ), weaker and further east compared to the HWM situation. The anticyclonic anomaly has 

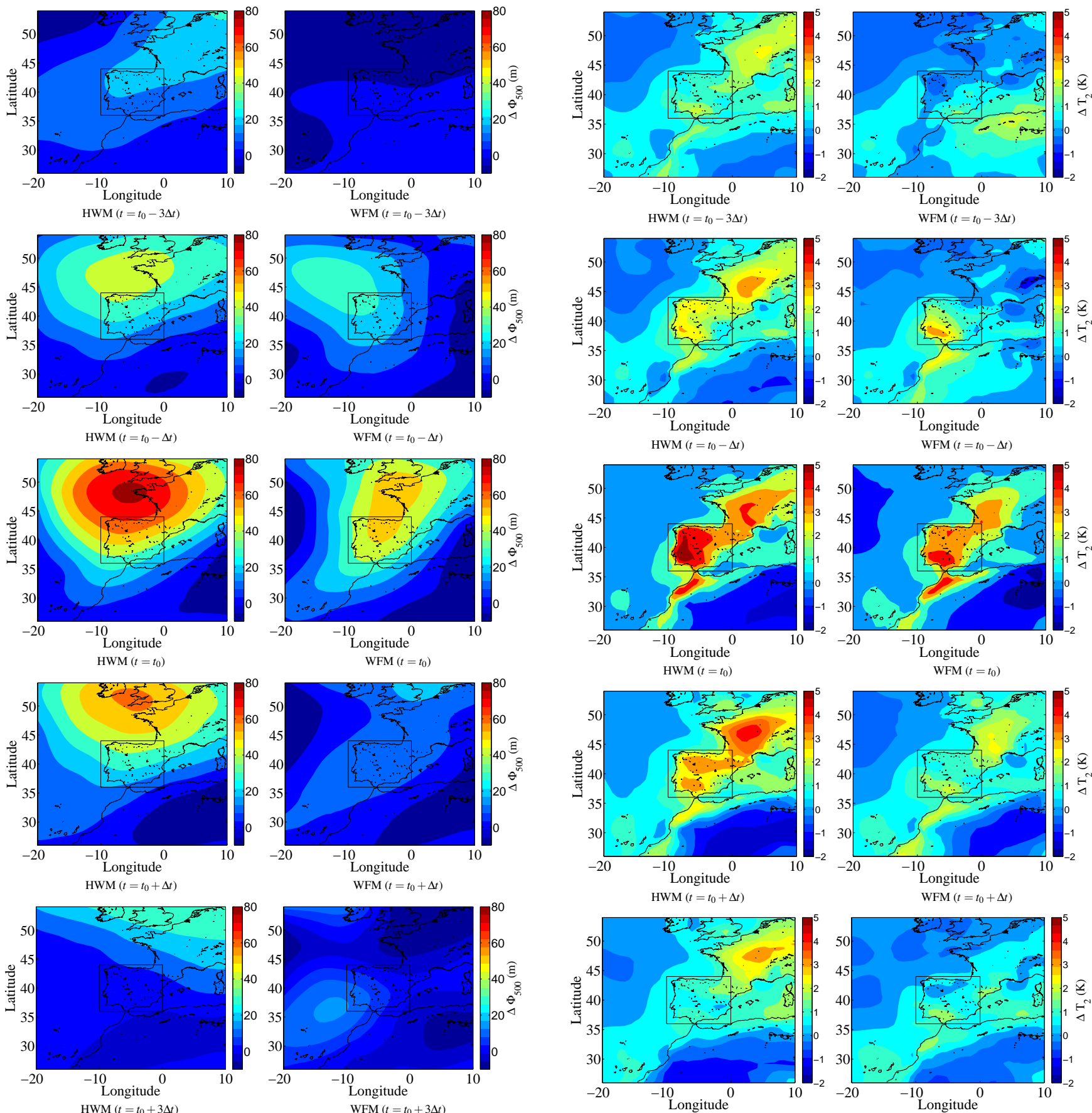

Figure 6. Composites over the Iberian Peninsula of the 500-hPa geopotential anomaly $\left(\Delta \Phi_{500}\right)$ for HWM (left column) and WFM (right column) wildfires at time $t_{0}-3 \Delta t$ (first row from top), $t_{0}-\Delta t$ (second row from top), $t_{0}$ (third row from top), $t_{0}+\Delta t$ (fourth row from top) and $t_{0}+3 \Delta t$ (fifth row from top). The composites are computed using the BA diagnostic.

almost totally disappeared at the end of the wildfire episode $\left(t_{0}+\Delta t\right)$. The striking result here is that the time sequence is chosen based on the fire life cycle only (initiation date and
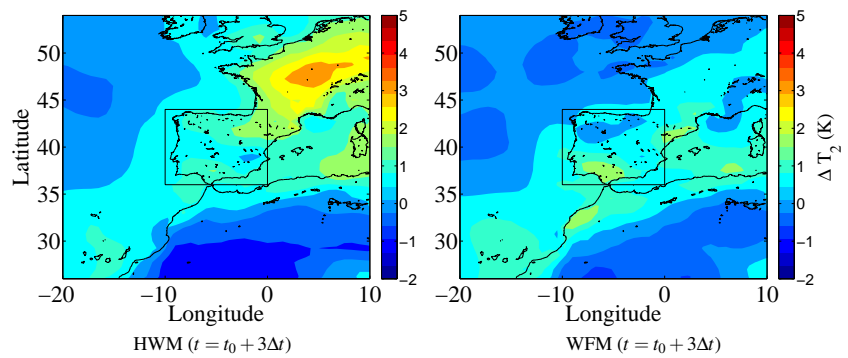

Figure 7. Same as Fig. 6 for the 2-m air temperature anomaly $\left(\Delta T_{2}\right)$.

fire duration). Figure 7 shows the temperature anomaly time sequences, following the same methodology than Fig. 6. The sequence is very similar to that of the geopotential with a very fast build-up and disappearance in the WFM situation and a slightly longer anomaly in the HWM situation. The maximum temperature anomaly is found during the wildfire 

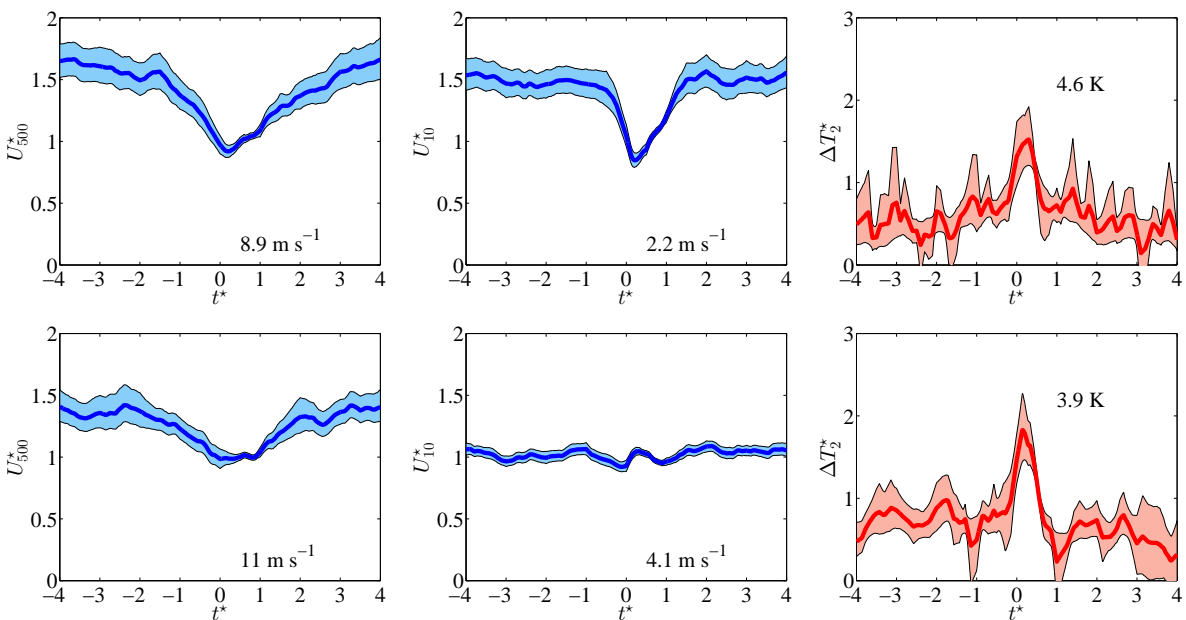

Figure 8. Composite of the time evolution of the wind speed at 500-hPa and 10-m levels and the 2-m air temperature anomaly for the whole Mediterranean region, based on the BA diagnostic for the HWM (upper row) and WFM (lower row) wildfires. The plotted values are normalized according to Eq. (1). Normalized time $t^{*}=0$ and $t^{*}=1$ correspond to the starting and ending dates of the wildfire activity, respectively. The value of $\overline{\left\|U_{500}\right\|}, \overline{\Delta T_{2}}$ and $\overline{\left\|U_{10}\right\|}$ are indicated in each sub-panel. Blue figures are plotted with their $99 \%$ confidence intervals and red figures with their $90 \%$ confidence intervals.

activity (between $t_{0}$ and $t_{0}+\Delta t$ ). Student's $t$ tests were performed on Figs. 6 and 7 to determine if the composites were different from the climatology and if composite maps from HWM and WFM were statistically different. We find that they are at the $99.9 \%$ confidence level. So despite the accidental or criminal nature of these wildfires, the correlation between the duration of the fire episode and of the synoptic favorable conditions is high and statistically significant.

Such finding is not specific to the Iberian Peninsula. Such behavior has been found in other sub-regions. To illustrate this point, Fig. 8 shows the time evolution of the wind speed at the $500-\mathrm{hPa}$ and $10-\mathrm{m}$ levels and the 2-m air temperature anomaly for the whole Mediterranean region, based on the BA diagnostic (the results are similar with FRP and will not be shown for concision). We selected only wildfires which duration is longer than 1 day and shorter than 10 days $(\approx 50 \%$ of BA-detected wildfires and $\approx 20 \%$ of FRP-detected wildfires). To compute a composite over the whole Mediterranean region, some normalization is needed. The normalized variables plotted in Fig. 8 are:

$U_{500}^{*}=\frac{\left\|U_{500}\right\|}{\left\|U_{500}\right\|} ; \quad U_{10}^{*}=\frac{\left\|U_{10}\right\|}{\overline{\left\|U_{10}\right\|}} ;$

$\Delta T_{2}^{*}=\frac{\Delta T_{2}}{\overline{\Delta T_{2}}} ; \quad t^{*}=\frac{t-t_{0}}{\Delta t}$,

with $\left.\bar{X}=\left.\operatorname{mean}(X)\right|_{t^{*} \in[0} 1\right]$ and where $U_{10}, U_{500}$ and $\Delta T_{2}$ are the wind speed at $10-\mathrm{m}$ and $500-\mathrm{hPa}$ levels and the 2-m air temperature anomaly, respectively.

So $t^{*}=0$ and $t^{*}=1$ are the starting and ending dates of the wildfire activity, respectively. Figure 8 shows the $99 \%$ confidence intervals for $U_{500}^{*}$ and $U_{10}^{*}$ and the $90 \%$ confidence intervals for $\Delta T_{2}^{*}$. As for Fig. 3, these confidence lev- els correspond to the maximum level of significance possible. They were determined using 5000 bootstrap resamplings. One can notice that $\Delta T_{2}^{*}$ is positive well before and after the wildfire. HWM and WFM wildfires therefore happen during periods when the temperature is already anomalously high. Indeed, long periods of high temperatures in heatwaves in summer in the Mediterranean region are associated with droughts (Stéfanon et al., 2012a), which in turns tends to lower the fuel moisture content and kill some of the vegetation. Fire can therefore propagate more easily in these situations. The temperature anomaly increases very sharply at $t^{*}=0$ and gets back to its pre-fire value at $t^{*}=1$ for both HWM and WFM wildfires. Wildfire initiation and end perfectly match the duration of the heatwave episodes, characterized by extremely hot temperature anomalies. The mean value of $\Delta t$ is 3.3 and 2.2 days for BA and FRP diagnostics, respectively, which are typical durations of mid-latitude weather regimes. As seen over the Iberian Peninsula, the surface temperature anomaly is strongly related to the $500-\mathrm{hPa}$ geopotential height and thus the geostrophic wind speed at the 500-hPa pressure level $\left(\left\|U_{500}\right\|\right)$. The 500-hPa air circulation slows down gradually, attains a minimum during the wildfire (roughly at the beginning) and this circulation accelerates back to its previous levels after the wildfire stops. The relative difference between the maximum and the minimum of the 500-hPa wind speed is slightly larger in HWM situation, indicating stronger deceleration. A similar evolution is found for the wind speed at the 10-m level for the HWM wildfires. For WFM wildfires, the evolution is different. The wind speed at the 10-m level does not evolve much with time. A weak decrease of the wind speed is visible during the wildfire activity followed by a weak increase but undoubtedly the 
blocking high associated to WFM wildfires is much weaker than for HWM wildfires.

\section{Conclusions}

This study shows that in the Mediterranean large wildfires are associated with a blocking situation as already reported in the literature (Pereira et al., 2005). In detail, the intensity of the blocking defines two types of wildfires. Fast build-up of a weak blocking produces intense wildfires associated with strong winds which allow propagation over long distances. Statistically, these wildfires, referred to as wind-forced mode (WFM) wildfires in this study, are shorter than those occurring in the absence of strong winds, called heatwave mode (HWM) wildfires in this study. The HWM wildfires are associated with a stronger blocking high which build-up extends over a slightly longer time period, which eventually end-up with a burnt area similar to those cause by WFM wildfires. The processes controlling the propagation of these two types of wildfires in the Mediterranean have been analyzed theoretically in Hernandez et al. (2015). This study also goes one step further with respect to the determination of the favorable synoptic conditions associated with the Mediterranean wildfires. Indeed, this study shows a near-perfect match between the period of wildfire activity and the persistence of the favorable synoptic conditions. In other words, statistically, the wildfire activity starts at the onset of the blocking situation which intensity controls the type of wildfire (HWM or WFM) and ends with the transition to less favorable synoptic weather pattern. So despite the accidental and criminal nature of the wildfires in the Mediterranean, there is an extremely strong control of the concomitant weather on the wildfire, whether it be on its extension or intensity. Such a result is very promising regarding fire risk forecast and management in the Mediterranean region.

Acknowledgements. This work contributes to the HyMeX program (HYdrological cycle in The Mediterranean EXperiment, Drobinski et al., 2014) through INSU-MISTRALS support and the GEWEX hydroclimate panel of the World Climate Research Program (WCRP). Data were provided by the European Forest Fire Information System - EFFIS (http://effis.jrc.ec.europa.eu) of the European Commission Joint Research Center.

The topical editor V. Kotroni thanks one anonymous referee for helping in evaluating this paper.

\section{References}

Aguado, I., Chuvieco, E., Borén, R., and Nieto, H.: Estimation of dead fuel moisture content from meteorological data in Mediterranean areas, Applications in fire danger assessment, Int. J. Wildland Fire, 16, 390-397, 2007.

Carmo, M., Moreira, F., Casimiro, P., and Vaz, P.: Land use and topography influences on wildfire occurrence in northern Portugal, Landscape Urban Plan., 100, 169-176, 2011.

Castro, F., Tudela, A., and Sebastià, M.: Modeling moisture content in shrubs to predict fire risk in Catalonia (Spain), Agricult. Forest Meteorol., 116, 49-59, 2003.

Dee, D., Uppala, S., Simmons, A., Berrisford, P., Poli, P., Kobayashi, S., Andrae, U., Balmaseda, M., Balsamo, G., Bauer, P., Bechtold, P., Beljaars, A. C. M., van de Berg, L., Bidlot, J., Bormann, N., Delsol, C., Dragani, R., Fuentes, M., Geer, A. J., Haimberger, L., Healy, S. B., Hersbach, H., Hólm, E. V., Isaksen, L., Kållberg, P., Köhler, M., Matricardi, M., McNally, A. P., Monge-Sanz, B. M., Morcrette, J.-J., Park, B.-K., Peubey, C., de Rosnay, P., Tavolato, C., Thépaut, J.-N., and Vitart, F.: The ERA-Interim reanalysis: Configuration and performance of the data assimilation system, Q. J. Roy. Meteor. Soc., 137, 553-597, 2011.

Drobinski, P., Ducrocq, V., Alpert, P., Anagnostou, E., Béranger, K., Borga, M., Braud, I., Chanzy, A., Davolio, S., Delrieu, G., Estournel, C., Filali Boubrahmi, N., Font, J., Grubisic, V., Gualdi, S., Homar, V., Ivancan-Picek, B., Kottmeier, C., Kotroni, V., Lagouvardos, K., Lionello, P., Llasat, M. C., Ludwig, W., Lutoff, C., Mariotti, A., Richard, E., Romero, R., Rotunno, R., Roussot, O., Ruin, I., Somot, S., Taupier-Letage, I., Tintore, J., Uijlenhoet, R., and Wernli, H.: HyMeX, a 10-year multidisciplinary program on the Mediterranean water cycle, B. Am. Meteorol. Soc., 95, 1063-1082, 2014.

EFFIS: Forest Fires in Europe - 2003 fire campaign, Joint Research Center, European Commission, available at: http://forest.jrc.ec. europa.eu/effis/reports/annual-fire-reports/ (last access: 27 July 2015), 2003.

European Commission: Forest Fires in Europe 2009, Office for Official Publication of the European Communities, Luxembourg, EUR 24502 EN, 81, 2010.

Flannigan, M. D. and Harrington, J.: A study of the relation of meteorological variables to monthly provincial area burned by wildfire in Canada (1953-80), J. Appl. Meteorol., 27, 441-452, 1988.

Flannigan, M. D. and Wotton, B. M.: Climate, weather, and area burned, Forest fires, New York: Academic Press, 73, 351 pp., 2001.

Flannigan, M. D., Krawchuk, M. A., de Groot, W. J., Wotton, B. M., and Gowman, L. M.: HyMeX, a 10-year multidisciplinary program on the Mediterranean water cycle, Int. J. Wildland Fire, 18, 483-507, 2009.

Ganteaume, A., Camia, A., Jappiot, M., San-Miguel-Ayanz, J., Long-Fournel, M., and Lampin, C.: A review of the main driving factors of forest fire ignition over Europe, Environ. Manage., 51, 651-662, 2013.

Giglio, L., Randerson, J. T., van der Werf, G. R., Kasibhatla, P. S., Collatz, G. J., Morton, D. C., and DeFries, R. S.: Assessing variability and long-term trends in burned area by merging multiple satellite fire products, Biogeosciences, 7, 1171-1186, doi:10.5194/bg-7-1171-2010, 2010. 
Hernandez, C., Drobinski, P., Turquety, S., and Dupuy, J.-L.: Size of wildfires in the Euro-Mediterranean region: observations and theoretical analysis, Nat. Hazards Earth Syst. Sci., 15, 13311341, doi:10.5194/nhess-15-1331-2015, 2015.

Hoinka, K. P., Carvalho, A., and Miranda, A. I.: Regional-scale weather patterns and wildland fires in central Portugal, Int. J. Wildland Fire, 18, 36-49, 2009.

Ichoku, C., Giglio, L., Wooster, M. J., and Remer, L. A.: Global characterization of biomass-burning patterns using satellite measurements of fire radiative energy, Remote Sens. Environ., 112, 2950-2962, 2008.

Le Houérou, H. N.: Vegetation wildfires in the Mediterranean basin: evolution and trends., Ecologia Mediterranea, XIII, 13, 13-24, 1987.

Levin, N. and Saaroni, H.: Fire weather in Israel - synoptic climatological analysis, GeoJournal, 47, 523-538, 1999.

Matthews, S.: A process-based model of fine fuel moisture, Int. J. Wildland Fire, 15, 155-168, 2006.

Pereira, M. G., Trigo, R. M., da Camara, C. C., Pereira, J., and Leite, S. M.: Synoptic patterns associated with large summer forest fires in Portugal, Agricult. Forest Meteorol., 129, 11-25, 2005.

Rothermel, R. C.: A mathematical model for predicting fire spread in wildland fuels, USDA Forest Service Research Paper INT115, Intermountain Forest And Range Experiment Station, US Department of Agriculture, Ogden, Utah, USA, 40 pp., 1972.

San-Miguel-Ayanz, J., Moreno, J. M., and Camia, A.: Analysis of large fires in European Mediterranean landscapes: lessons learned and perspectives, Forest Ecol. Manage., 294, 11-22, 2013.

Sedano, F., Kempeneers, P., San Miguel, J., Strobl, P., and Vogt, P.: Towards a pan-European burnt scar mapping methodology vased on single date medium resolution optical remote sensing data, Int. J. Appl. Earth Obs., 20, 52-59, 2013.

Sharples, J., McRae, R., Weber, R., and Gill, A.: A simple index for assessing fuel moisture content, Environ. Model. Softw., 24, 637-646, 2009.

Silva, J. S., Rego, F., Fernandes, P., and Rigolot, E.: Towards integrated fire management: outcomes of the European project Fire Paradox, European Forest Institute, Joensuu, Finland, 2010.
Stéfanon, M., D’Andrea, F., and Drobinski, P.: Heatwave classification over Europe and the Mediterranean region, Environ. Res. Lett., 7, 014023, doi:10.1088/1748-9326/7/1/014023, 2012a.

Stéfanon, M., Drobinski, P., D’Andrea, F., and Noblet-Ducoudré, N.: Effects of interactive vegetation phenology on the 2003 summer heat waves, J. Geophys. Res., 117, D24103, doi:10.1029/2012JD018187, 2012b.

Stéfanon, M., Drobinski, P., D’Andrea, F., Lebeaupin-Brossier, C., and Bastin, S.: Soil moisture-temperature feedbacks at mesoscale during summer heat waves over Western Europe, Clim. Dynam., 42, 1309-1324, 2014.

Turquety, S., Menut, L., Anav, A., Viovy, N., Maignan, F., and Wooster, M.: APIFLAME v1. 0: high-resolution fire emission model and application to the Euro-Mediterranean region, Geosci. Model Develop., 7, 587-612, 2014.

UNEP (United Nations Environment Program): Impacts of Summer 2003 Heat Wave in Europe, DEWA/ Europe/GRIDGeneva: UNEP, available at: http://www.grid.unep.ch/products/ 3_Reports/ew_heat_wave.en.pdf (last access: 27 July 2015), 2004.

Val Martin, M., Logan, J. A., Kahn, R. A., Leung, F.-Y., Nelson, D. L., and Diner, D. J.: Smoke injection heights from fires in North America: analysis of 5 years of satellite observations, Atmos. Chem. Phys., 10, 1491-1510, doi:10.5194/acp-10-14912010, 2010.

Wooster, M. J., Roberts, G., Perry, G., and Kaufman, Y.: Retrieval of biomass combustion rates and totals from fire radiative power observations: FRP derivation and calibration relationships between biomass consumption and fire radiative energy release, J. Geophys. Res.-Atmos., 110, D24311, doi:10.1029/2005JD006318, 2005.

Zaitchik, B. F., Macalady, A. K., Bonneau, L. R., and Smith, R. B.: Europe's 2003 heat wave: a satellite view of impacts and landatmosphere feedbacks, Int. J. Climatol., 26, 743-769, 2006. 